тентности студентов в процессе обучения иностранному языку // Азимут научных исследований: педагогика и психология. 2014. № 1. С. 49-51.

34. Павловская Н.Г. Исследование коммуникативной компетентности - аспекта конкурентоспособности будущих бакалавров образования // Карельский научный журнал. 2015. № 2 (11). С. 45-49.

35. Толикина Е.А. Формирование коммуникативной компетенции студентов посредством интегративного курса литературы // Балтийский гуманитарный журнал. 2015. № 3 (12). С. 71-74.

36. Иващенко О.А. Формирование иноязычной коммуникативной компетенции будущих специалистов государственной службы по чрезвычайным ситуациям // Азимут научных исследований: педагогика и психология. 2013. № 1. С. 20-23.

37. Смирнова Е.В. Формирование коммуникативного пространства языковой среды в условиях иноязычного информационного и коммуникационного взаимодействия // Балтийский гуманитарный журнал. 2013. № 2. С. 33-36.

38. Хуторской А.В. Ключевые компетенции и образовательные стандарты [Электронный ресурс] // Интернет-журнал «Эйдос». 2002, 23 апреля. http://eidos.ru/journal/2002/0423.htm.

\title{
FEATURES OF A COMPETENCY APPROACH TO THE UNIVERSITY EDUCATION CONTENT IMPLEMENTATION
}

\section{(C) 2016}

N.N. Semenova, senior lecturer of Information and Communication Technologies in Education Department Samara State University of Social Sciences and Education, Samara (Russia)

Abstract. The following paper deals with the reasons for the reorganization of the educational system, as well as the reasons for updating the content of education and technology. The author describes the goals of modern education, the problems of future teacher training, the problems of the Russian education system modernization, requirements for graduates of higher education institutions, the reasons of the transition from the knowledge and skills to competences, the content of the competence concept with respect to educational activities, the problems of professional competence development at graduates whose major is Teacher Education, the process of future teacher professional competence development. The author states that the competence approach implementation will affect the quality of education. The paper also deals with the problem of raising the level of future teacher professional competence. Crucial competencies are described. The paper contains the definition of professional competence, focusing on the professional competence of the teacher, the definition of value-semantic competence, general cultural competence, educational and cognitive competence, informational competence, communicative competence. The article analyzes the problems of competencebased approach implementation in the educational system, as well as the necessity of educational activities content change in higher education institutions.

Keywords: competence approach; knowledge; skills; competence; the purpose of education; professional competence; crucial competencies; values and sense of competence; general cultural competence; educational and cognitive competence; informational competence; communicative competence.

\section{УДК 378}

\section{СРЕДСТВА УПРАВЛЕНИЯ КАЧЕСТВОМ САМОСТОЯТЕЛЬНОЙ РАБОТЫ СТУДЕНТОВ}

(C) 2016

Н.Б. Стрекалова, кандидат педагогических наук, доцент кафедры теории и методики профессионального образования Самарский национальный исследовательский университет имени академика С.П. Королёва, Самара (Россия)

Аннотация. В статье рассматривается самостоятельная работа студентов как важный фактор высшего образования. Описываются специфика и особенности выполнения самостоятельной работы студентов в условиях электронного обучения, расширения дистантных форм обучения и переноса учебного процесса в Интернет. Определяется суть самостоятельной работы студентов и влияния на нее образовательных рисков разной природы. С опорой на международные стандарты ИСО, определяющие главную задачу обеспечения качества как управление возникающими в ходе его достижения рисками, делается вывод о возможности обеспечения качества самостоятельной работы студентов педагогическими средствами управления. Поиск педагогических средств управления качеством самостоятельной работы студентов осуществлялся на базе Тольяттинской академии управления, в которой опыт применения открытой информационно-образовательной среды составляет более 10 лет. Результаты исследования показали, что эффективное управление качеством самостоятельной работы студентов в новых условиях протекания учебного процесса требует осуществления трех разных видов управления: опосредованного педагогического, самоуправления студентом и совместного управления преподавателя и студента - и, соответственно, разных педагогических средств. Полученные материалы могут служить основой для повышения качества не только самостоятельной работы студентов, но и высшего образования в целом.

Ключевые слова: самостоятельная работа студентов; управление; управленческая триада; опосредованное педагогическое управление; самоуправление; соуправление; образовательные риски; средовой подход; партисипативное управление; субъектность; полисубъект; открытая образовательная среда. 
Российскому обществу необходимо качественное высшее образование для выхода страны на передовые позиции мирового рынка и повышения уровня жизни населения [1]. В условиях информатизации общества значимыми образовательными результатами профессиональной подготовки специалистов становятся такие умения: самостоятельно добывать, оценивать, анализировать, классифицировать информацию; осваивать и применять в своей профессиональной деятельности новые информационные технологии; самостоятельно повышать уровень своего образования. В результате самостоятельная работа становится значимым фактором высшего образования [2; 3], в образовательных программах увеличивается объем самостоятельной работы студентов и актуализируется проблема обеспечения ее качества.

Педагоги (С.Н. Боженов [4], Т.В. Колесова [5], Т.А. Куликова [6], И.В. Харитонова [7], Г.Н. Юшко [8]) определяют составляющие качества самостоятельной работы и разрабатывают средства его мониторинга, рассматривают суть самостоятельной работы студентов с новых позиций: в единстве организационной формы обучения и деятельности студентов; в единстве двух качеств - объекта деятельности и формы деятельности; как явление, в котором самостоятельная работа одновременно выступает методом, средством и формой обучения. Потребность в рассмотрении сути самостоятельной работы с новых позиций обусловлена стремлением раскрыть ее характерные признаки, адекватные современным задачам образования, повысить эффективность педагогического руководства и качество ее выполнения в современных условиях протекания учебного процесса. Однако, по мнению исследователей дидактики [9], в научных материалах представлены только отдельные аспекты данной проблемы, но единая концепция организации самостоятельной работы так до конца и не сформирована.

Целью нашего исследования стало выявление сути современной самостоятельной работы студентов, уточнение специфики и особенностей ее выполнения, поиск педагогических средств, позволяющих создать условия для выполнения самостоятельной работы на качественном уровне.

По мнению ученых [10], изучение педагогических явлений целесообразно осуществлять в логике деятельностного подхода, через целостное рассмотрение потребностей и мотивов выполняемой деятельности, ее целей и операций, способов регулирования, контроля и анализа результатов, что позволит уточнить ее суть, определить условия формирования образовательных результатов и повысить качество профессиональной подготовки. В условиях новой образовательной парадигмы целью (и мотивом) обучения в целом и самостоятельной работы студентов в частности становится «добывание» учебной информации и построение на ее основе нового знания, а предметом выступают подлежащие осмыслению большие массивы информации. Развитие электронных средств обучения, фактический перенос учебного процесса в Интернет и открытые образовательные среды обусловили широкое применение информационно-коммуникационных технологий, открытых электронно-образовательных ресурсов, сетевых технологий, технологий Web 2.0 в самостоятельной работе студентов [11]. Все это позволяет представить суть современной самостоятельной работы как информационно-исследовательскую деятельность студентов по формированию нового знания, специфика которой заключается в применении особых инструментов - современных информационно-коммуникационных и сетевых технологий.

Особенности выполнения самостоятельной работы обусловлены неограниченным доступом студентов к информационным ресурсам Интернет и открытых образовательных сред, ситуацией постоянного увеличения изучаемого материала, возможностью построения уникальной траектории «добывания знаний» и отсутствием каких-либо ограничений на ход выполнения работ [12]. Анализ данных условий позволил выделить следующие группы особенностей самостоятельной работы студентов: технологические - связаны с возможностью выбора участниками учебного процесса любых технических средств для выполнения учебного задания и доступа к информационным ресурсам; организационные - обусловлены отсутствием пространственных (в любом месте), временнь́х (в любое время) и методических (с любой скоростью и интенсивностью) ограничений на выполнение самостоятельной работы; методические - обусловлены неограниченным объем изучаемых материалов и их свободным выбором, в результате чего формируется уникальная траектория «добывания знаний» и индивидуальные результаты обучения у каждого студента; культурологические - обусловлены отсутствием общепринятых норм сетевой этики и разнообразием культурных и ценностных ориентаций в Интернет.

В ходе исследования установлено, что выявленные особенности взаимодетерминированы рядом негативных последствий - информационной зависимостью и информационной перегрузкой студентов, в которых находит свое отражение мировая проблема развития рискогенного общества. Современные ученые [13; 14] определяют риск как совокупность процессов, оказывающих деструктивно-трансформирующее воздействие на любую систему функционирования, как феномен, который может приводить и к отрицательным, и к положительным последствиям, как ситуацию неопределенности в отношении ожидаемого результата. По мнению педагогов [15], образовательный риск необходимо представлять мерой реальности нежелательного развития событий из-за объективно существующей неопределенности. В данном исследовании под образовательным риском понимаем потенциальное отклонение (негативное или позитивное) формируемых образовательных результатов от запланированных, происходящее под воздействием факторов разной природы. Экстраполяция данного определения на самостоятельную работу и особенности ее выполнения позволяет говорить о существовании образовательных рисков ее выполнения: технологических (свободный выбор технологий для выполнения самостоятельной работы упрощает ее выполнение, но приводит к проблеме корректной проверки работы и ее адекватной оценки); организационных (отсутствие ограничений по времени может приводить к несвоевременному поступлению работ на проверку и снижению оценки); методических (неограниченный выбор изучаемых материалов, уникальная траектория 
«добывания знаний» способствуют отклонению результатов работы от замысла преподавателя и развитию информационных перегрузок студентов); коммуникативных (отсутствие общепринятых норм сетевой этики, несформированность в образовательной сфере правил сетевого взаимодействия участников учебного процесса создают проблемы взаимопонимания в виртуальной переписке, своевременности обратной связи, сохранности работ студентов).

Выход проблемы неопределенности и рисков на глобальный социальный уровень потребовал от общества разработки нового международного стандарта в области качества ИСО 9001:2015, в соответствии с которым улучшить качество деятельности можно через управление ее рисками, их своевременное выявление и выполнение соответствующих упреждающих действий. Таким образом, управление становится главным средством обеспечения качества современной самостоятельной работы студентов, что обусловило более глубокое научно-методическое изучение данного вопроса.

По мнению ученых [16], самостоятельная работа студентов - это не самообразование индивида по собственному произволу, а систематическая, управляемая преподавателем деятельность студента. В ходе исследования установлены функции преподавателя, необходимые для организации современной самостоятельной работы студентов (ее планирование, методическое обеспечение, технологическая организация, координация совместной деятельности со студентом, контроль результатов), среди которых функция координации принимает системоформирующий характер. В то же время самостоятельная работа как средство и форма организации учебно-познавательной деятельности требует самоуправления студентом данным процессом. В ходе пилотных исследований выявлено, что большинство современных студентов не умеют планировать время и не могут организовать правильно свою деятельность. Определено, что для самоуправления самостоятельной работой студентам необходимы знания и навыки: самомотивации - установки на достижение поставленных целей и активизации личностных способностей; самоорганизации планирования работ, организации личного времени и пространства, выбора технологий для решения задач; самоконтроля - выполнения мониторинга за ходом и промежуточными результатами работы, осуществления адекватной реакции на существующие обстоятельства, отказов от непродуктивных действий; самооценки - оценивания результатов работы, осознания ее плюсов и минусов, мотивации на более активную деятельность. Вместе с тем, с учетом особой роли педагогической функции координации совместной деятельности сделано предположение об актуальности совместного управления преподавателя и студента самостоятельной работой, их партнерства и сотворчества. В научных исследованиях [17] соуправление представляется в виде процесса позитивного взаимодействия, координации и кооперации элементов открытой неравновесной кластерной системы «учитель - ученик - родитель». Объединение данных определений позволило представить «соуправление» в контексте самостоятельной работы как позитивное взаимодействие нескольких субъектов управления (пре- подавателя и студента) в целях выработки оптимального подхода к выполнению самостоятельной работы. Очевидно, что опосредованное педагогическое управление, самоуправление и соуправление являются разновидностями управления как такового, предполагая целенаправленное воздействие на один и тот же объект управления (самостоятельная работа) разными субъектами управления (преподаватель, студент, сообщество «преподаватель - студент»), формируя взаимодействующие звенья одной цепи. Выявленная взаимосвязь процессов «опосредованное педагогическое управление», «соуправление» и «самоуправление» сделала возможным их объединение в управленческую триаду, выступающую в итоге средством управления качеством самостоятельной работы студентов.

Различие субъектов управления потребовали конкретизации педагогических средств управления качеством самостоятельной работы студентов. Так, опосредованное педагогическое управление самостоятельной работой студентов должно осуществляться на принципах средового подхода [18], обладающего потенциальными возможностями управления стихийными проявлениями различных сред (Интернет, открытой образовательной среды), образовательными рисками выполнения самостоятельной работы студентов в них, опосредованного влияния на деятельность студента и качество его работы. Основой опосредованного педагогического управления выступает план средоуправленческих действий, поддерживающих активность студентов и возникающие позитивные стихии в среде, разрушающих негативные стихии среды и упреждающих появление образовательных рисков выполнения самостоятельной работы студентами [19]. Для снижения интенсивности учебной нагрузки на студента и упреждения его информационной перегрузки необходимо выполнять расчёт времени, отводимого на выполнение самостоятельной работы, предоставлять студентам подробный план самостоятельных работ с указанием бюджета времени на каждую из них.

В ходе исследования установлено, что самоуправление студентом самостоятельной работой требует развития его субъектности (способности к самоупорядочиванию своей деятельности, мобилизации собственных сил, саморазвитию в области информационных технологий, исследовательских методик и приемов), а соуправление преподавателя и студента - становления полисубъекта «преподаватель - студент». Реализация этих задач возможна с опорой на принципы партисипативного управления (принцип субъектности обеспечивает самостоятельность деятельности и проявление творческих способностей при выполнении работы; принцип непрерывности развития обусловливает постепенное и постоянное развитие субъектности студента и полисубъекта «преподаватель студент», повышение их ИКТ-грамотности; принцип полисубъектности взаимодействия обеспечивает конструктивный диалог студента и преподавателя, их партнерство и сотрудничество; принцип коллегиальности управления предполагает совместное принятие решений, коллективную и личную ответственность за них) и принцип оптимальной открытости обучения, позволяющий учитывать особенности выполнения 
самостоятельной работы студентов. Ответственность за соблюдение данных принципов несет преподаватель как организатор самостоятельной работы, что требует от него выполнения методических приемов ведения коммуникационного взаимодействия со студентом. Считаем, что такое взаимодействие должно осуществляться с опорой на особые педагогические техники и принципы [20]: ориентации на понимание как сообщения, так и партнера по коммуникации; содержательной доступности информации как по сложности, так и по каналу; содержательной безопасности для предотвращения возможных психофизиологических и социально-психологических деформаций личности; общности целей и интересов, значимости партнера и регуляции эмоционального напряжения.

Таким образом, управление качеством самостоятельной работы студентов должно учитывать ее суть, специфику и особенности выполнения в новых условиях протекания учебного процесса, возникающие при этом образовательные риски. Основным средством управления становится управленческая триада, предполагающая выполнение взаимодействующих процессов опосредованного педагогического управления, самоуправления студентом и соуправления преподавателя и студента. Необходима дальнейшая конкретизация педагогической реализации управленческой триады в учебном процессе.

\section{СПИСОК ЛИТЕРАТУРЫ:}

1. О Концепции долгосрочного социально-экономического развития РФ на период до 2020 года: распоряжение Правительства РФ № 1662-р от 17.11.2008 // Собрание законодательства РФ. 24.11.2008. № 47. ст. 5489.

2. Попова 3.Н. Самостоятельная работа студентов как способ интенсификации процесса овладения учебной дисциплиной «Музыка и методика преподавания» // Проблемы и перспективы развития образования в России: сборник материалов XII международной научно-практической конференции. Новосибирск: Изд-во НГТУ, 2011. С. 201-206.

3. Якушина Л.П. Технология организации внеаудиторной самостоятельной работы студентов в вузе: дис. ... канд. пед. наук. Орел, 2007. 210 с.

4. Боженов С.Н. Проблемы и перспективы использования технологий компьютерного тестирования для оценки качества самостоятельной работы студентов // Актуальные проблемы реализации образовательных стандартов нового поколения в условиях университетского комплекса: материалы Всероссийской научно-методической конференции. Оренбург: ОГУ, 2011. C. $1516-1520$.

5. Колесова Т.В. Информационные технологии обучения в повышении качества самостоятельной работы при обучении иностранному языку в вузе. Вест- ник РУДН. Серия: Информатизация образования. 2011. № 1. С. 19-23.

6. Куликова Т.А. Организация самостоятельной работы студентов вуза в информационно-коммуникационной обучающей среде: автореферат дис. ... канд. пед. наук. Ставрополь, 2011. с. 25.

7. Харитонова И.В. Организация самостоятельной работы студентов при обучении математике в вузе: дис. ... канд. пед. наук. Саранск, 1996.173 с.

8. Юшко Г.Н. Научно-дидактические основы организации самостоятельной работы студентов в условиях рейтинговой системы обучения: автореф. дис. ... канд. пед. наук. Ростов-н/Д., 2001. 23 с.

9. Макарова Н.С. Трансформация дидактики высшей школы. М.: Флинта, 2012. 180 с.

10. Руднева Т.И, Левченко В.В., Соловова Н.В., Стрекалова Н.Б. Методологические подходы к исследованию проблем в области профессиональной педагогики: коллективная монография. Самара: Изд-во «Самарский университет», 2013. 164 с.

11. Руднева Т.И, Стрекалова Н.Б. Социологическое сопровождение процесса организации самостоятельной работы студентов в условиях информатизации вузов // Социология образования. 2014. № 8. С. 4-13.

12. Стрекалова Н.Б. Учебный процесс в открытых информационно-образовательных средах // Высшее образование в России. 2014. № 1. С. 93-97.

13. Гидденс Э. Ускользающий мир: как глобализация меняет нашу жизнь М.: Весь мир, 2004. 120 с.

14. Маслов П.А. Проблемы управления рисками в современной России: автореферат дис. ... канд. соц. наук. Пятигорск, 2009. 21 с.

15. Чубарова О.И. Образовательный риск как экономическая категория, его сущность // Ползуновский вестник. 2005. № 1. С. 199-208.

16. Алтайцев А.М., Наумов В.В. Учебно-методический комплекс как модель организации учебных материалов и средств дистанционного обучения // Университетское образование: от эффективного преподавания к эффективному учению (Минск, 1-3 марта 2001 г.). Мн.: Пропилеи, 2002. С. 229-241.

17. Корсакова Т.А. Философско-праксиологические основы соуправления развитием личности: автореферат дис. ... канд. фил. наук. Якутск, 2003. 28 с.

18. Мануйлов Ю.С. Средовой подход в воспитании // Педагогика. 2000. № 7. С. 36-41.

19. Стрекалова Н.Б. Управление рисками самостоятельной работы студентов в открытой информационно-образовательной среде // Вестник Самарского государственного университета. Гуманитарная серия. 2015. № 11 (133). С. 220-225.

20. Сысоева Е.Ю. Коммуникативная культура преподавателя вуза. Самара: Изд-во «Самарский университет», 2014. 144 c.

\section{CONTROL FACILITIES QUALITY OF STUDENTS' INDEPENDENT WORK}

(C) 2016

N.B. Strekalova, candidate of pedagogical sciences,

associate professor of Theory and Methods of Professional Education Department Samara National Research University, Samara (Russia)

Abstract. The following paper deals with the independent work of students as an important factor of modern higher education. The author describes specifics and features of students' independent work accomplishment in the conditions of electronic training, distant education forms expansion and educational process transfer to the Internet. The essence 
Стрекалова Н.Б.

of students' independent work and influence of educational risks of different nature on it is determined. Taking into account the international standards ISO determining the main task of quality assurance as management of risks arising during its achievement, students' independent work quality can be provided with pedagogical controls. Search of pedagogical controls quality of students' independent work was performed in Tolyatti Academy of Management where they have been applying the open information and education environment for more than 10 years. The research results showed that effective management of students' independent work quality in new conditions of its accomplishment requires implementation of three different types of management - mediated pedagogical, self-government and comanaging, as well as different pedagogical means. The received materials can form a basis for quality improvement of students' independent work as well as of the higher education in general.

Keywords: independent work of students; management; managerial triad; the mediated pedagogical management; self-government; co-managing; educational risks; environmental approach; participative management; subjectivity; the poly-subject; the open educational environment. 